\title{
A rare cause of constrictive pericarditis
}

\author{
Shane Patrick Flood, ${ }^{1}$ Omar Ayah, ${ }^{1}$ Satoshi Furukawa, ${ }^{2}$ Robert B Norris ${ }^{3}$
}

${ }^{1}$ Department of Internal Medicine, Pennsylvania Hospital, Philadelphia, Pennsylvania, USA ${ }^{2}$ Department of Cardiovascular Surgery, Pennsylvania Hospital, Philadelphia, Pennsylvania, USA

${ }^{3}$ Cardiovascular Medicine Division, Pennsylvania Hospital, Philadelphia, Pennsylvania, USA

Correspondence to Dr Shane Patrick Flood, shane.flood@uphs.upenn.edu

Accepted 3 January 2017
CrossMark

\footnotetext{
To cite: Flood SP, Ayah 0 , Furukawa $\mathrm{S}$, et al. BMJ Case Rep Published online: [please include Day Month Year] doi:10.1136/bcr-2016216813
}

\section{SUMMARY}

A 67-year-old man presented with 3 months of exertional dyspnoea and 1 week of oedema. Examination revealed elevated neck veins, pulsus paradoxus, muffled heart sounds, decreased breath sounds and pedal oedema. Transthoracic echocardiogram (TTE) demonstrated cardiac tamponade, and chest X-ray showed pleural effusion. Pericardiocentesis,

thoracocentesis, laboratory investigations and CT did not elucidate an underlying aetiology. Three weeks later, he presented with recurrent cardiac tamponade and pleural effusion. Pericardial window histology was benign. Pleural and pericardial fluids were again unrevealing. Three months later, he presented with worsening congestive heart failure. TTE, cardiac catheterisation and cardiac MRI were consistent with constrictive pericarditis. Preoperative workup did not identify an underlying cause. The patient underwent subtotal pericardiectomy. Intraoperative frozen section indicated malignancy. Pathology confirmed metastatic poorly differentiated signet ring adenocarcinoma of intestinal origin. He died 4 days postoperatively from multiorgan failure.

\section{BACKGROUND}

Constrictive pericarditis (CP) is characterised by encasement of the heart by a rigid non-pliable pericardium, resulting in symptoms and signs of heart failure. It most commonly occurs as a late sequela of pericardial inflammation caused by prior infections, radiation or cardiothoracic surgery. We present a case of recurrent cardiac tamponade with serially negative investigations that developed into $\mathrm{CP}$, found to be secondary to occult gastrointestinal malignancy at pericardiectomy. This case highlights the challenges in diagnosing occult pericardial malignancy and the importance of clinical suspicion in recurrent pericardial disease of undetermined aetiology.

\section{CASE PRESENTATION}

A 67-year-old Caucasian man presented with 3 months of exertional dyspnoea and 1 week of pedal oedema. Medical history included gastrooesophageal reflux disease, colonic tubular adenoma diagnosed 2 weeks prior to presentation and childhood tuberculosis. Examination was significant for elevated neck veins, muffled heart sounds, pulsus paradoxus, decreased breath sounds and pedal oedema. ECG showed normal sinus rhythm with decreased voltages, and chest X-ray (CXR) showed a small right pleural effusion. Transthoracic echocardiogram (TTE) revealed a large anterior pericardial effusion, with diastolic chamber collapse suggestive of tamponade (figure 1). Pericardiocentesis yielded exudative pericardial fluid, negative for acid-fast bacilli (AFB), bacteria and malignant cells. A purified protein derivative (PPD) test was negative. CT chest, abdomen and pelvis following pericardiocentesis showed a $5 \mathrm{~mm}$ left apical calcified granuloma, scattered mediastinal and bilateral hilar calcifications and an anterior mediastinal soft tissue density thought likely to be postprocedural blood (figure 2). There were no CT findings of gastrointestinal malignancy.

Three weeks later, he presented with recurrent tamponade and right pleural effusion. Pericardial window and biopsy yielded bloody pericardial fluid with negative cultures and cytology. Histology showed benign fibroconnective and adipose tissue with negative AFB stain. A right thoracentesis revealed transudative effusion with negative cytology and cultures. He was treated with colchicine for recurrent idiopathic pericardial effusion.

Three months later, he represented with $4.5 \mathrm{~kg}$ weight gain, dyspnoea, orthopnoea, chest pain on exertion, elevated JVP, bibasilar rales and $2+$ pitting oedema. TTE revealed abnormal septal motion during diastole without significant pericardial effusion (figure 1). Cardiac catheterisation showed diastolic equalisation of pressures, decreased cardiac output and normal ejection fraction consistent with CP. Cardiac MRI showed diffuse pericardial thickening (figure 3), abnormal pericardial enhancement and impingement of the intraventricular septum into the left ventricle on inspiration, consistent with CP. There was interval decrease in conspicuity of the previously noted anterior mediastinal soft tissue density. A repeat right thoracentesis was negative for infectious and malignant aetiologies.

\section{TREATMENT}

The patient underwent off-pump subtotal pericardiectomy. Intraoperatively, the mediastinum was frozen with a fibrotic process. Frozen section

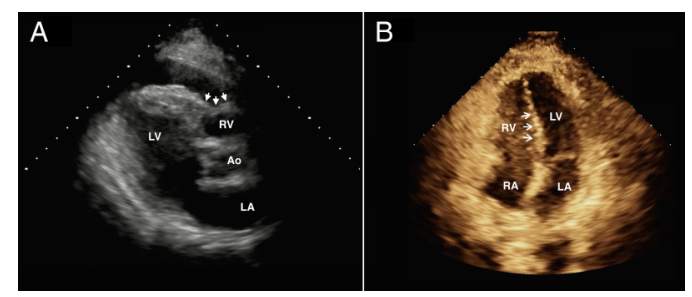

Figure 1 (A) Initial TTE showing right ventricular diastolic collapse consistent with cardiac tamponade (arrows). (B) Subsequent TTE showing abnormal septal diastolic movement suggestive of CP (line arrows). Ao, Aorta; CP, constrictive pericarditis; LA, left atrium; LV, left ventricle; $R A$, right atrium; $R V$, right ventricle; $T T E$, transthoracic echocardiogram. 

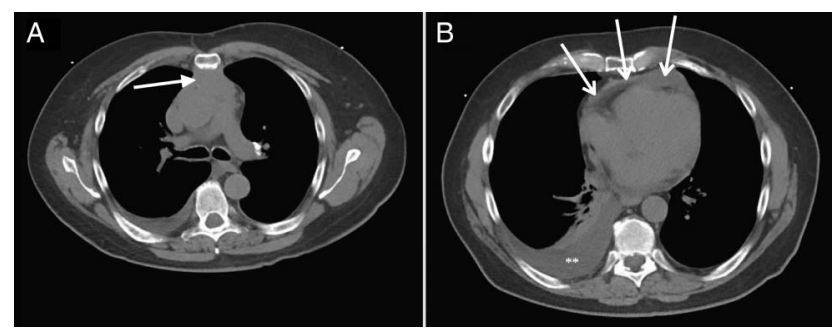

Figure 2 CT chest. (A) Mediastinal soft tissue density (arrow).

(B) Pericardial effusion (line arrow) and large right pleural effusion $\left(^{* *}\right)$.
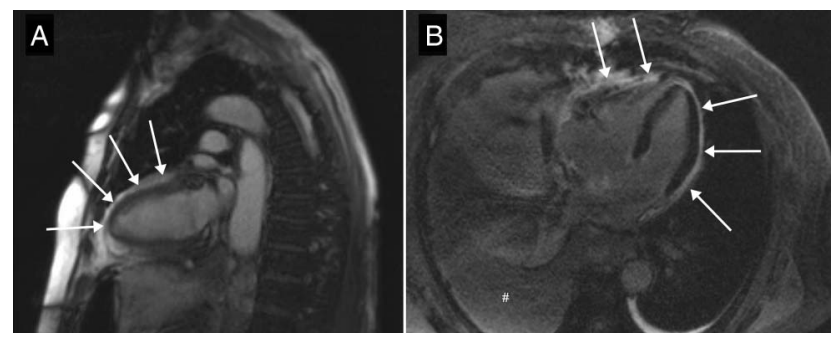

Figure 3 (A, B) Cardiac MRI. Pericardial thickening (arrows). (B) Pleural effusion (\#).

indicated malignancy. Histopathology (figure 4) and immunohistochemisty showed a metastatic poorly differentiated adenocarcinoma with signet ring features consistent with intestinal origin.

\section{OUTCOME AND FOLLOW-UP}

Postoperatively, the patient became haemodynamically unstable, requiring invasive mechanical ventilation and vasopressors. $\mathrm{He}$ requested a transition to hospice care and died 4 days postoperatively from multiorgan failure.

\section{DISCUSSION}

Metastases reach the heart by direct, transvenous, haematogenous or lymphatic routes, the latter often in pericardial disease. ${ }^{1}$ When symptomatic, they manifest as pericardial effusion or rarely CP. Autopsy studies show secondary cardiac tumours in $0.7-3.5 \%$ of the general population, $9.1 \%$ where a primary tumour is found and $14.2 \%$ with multiple metastases. This overestimates clinically significant disease, most cardiac metastases being asymptomatic. ${ }^{1}$ Two-thirds of cardiac metastases involve the pericardium, ${ }^{2}$ with aetiology: lung $40 \%$; breast $22 \%$; lymphoma and leukaemia 15\%; gastric and colon $3 \% .^{3}$ Symptomatic pericardial effusion may be the initial presentation of malignancy in one-fifth of patients with negative clinical findings and simple laboratory tests. ${ }^{4}$ Malignancy rarely causes $\mathrm{CP},{ }^{5}$ with a $2-5 \%$ risk following acute neoplastic pericarditis. ${ }^{6}$ A 2011 review detailed only three cases of signet ring gastric adenocarcinoma with initial presentation as cardiac tamponade. We found no similar cases of colorectal adenocarcinoma, or any cases of CP as the primary presentation of GI malignancy in the English medical literature. These data highlight that although rare there should be a low index of suspicion for malignancy when faced with a negative work-up.

Clinically, malignant pericardial effusion may range from asymptomatic to tamponade. Beck's triad (hypotension, elevated veins and muffled heart sounds) is not as common as with nonmalignant disease. ${ }^{5}$ ECG is non-specific, but large effusion can cause decreased voltages, and tamponade electrical alternans. ${ }^{6}$

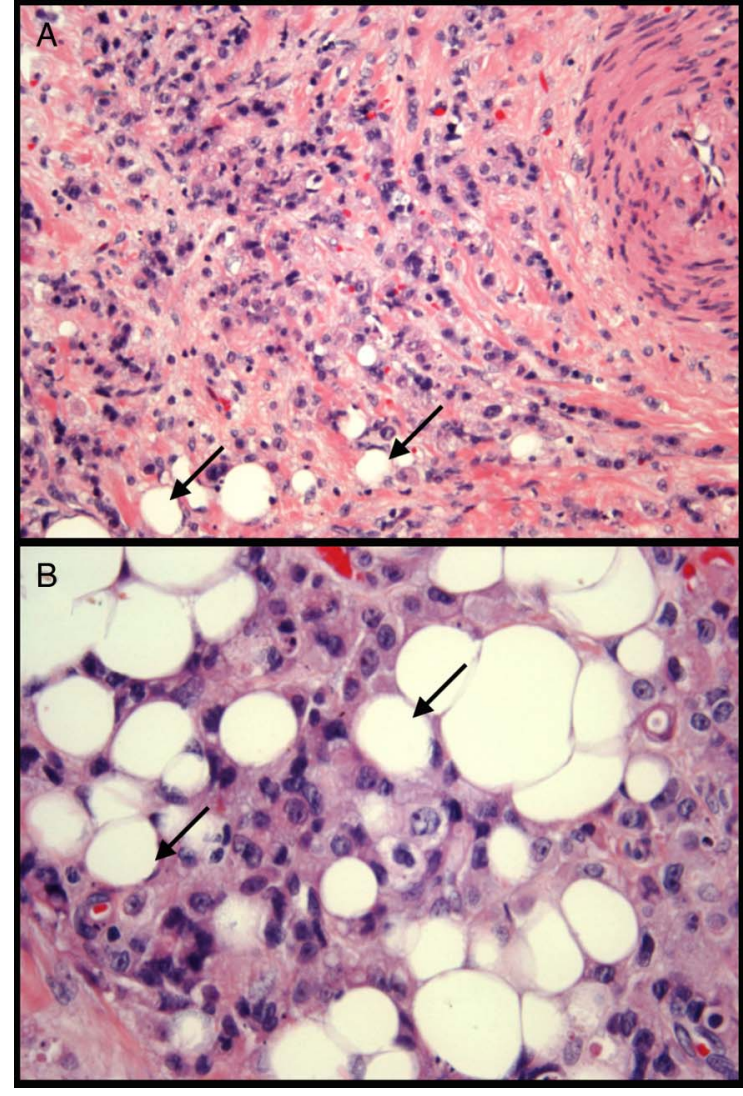

Figure 4 (A) Low and (B) high magnification, showing signet cells with clear cytoplasm and peripherally displaced nuclei (arrows).

TTE is the initial investigation of choice and highly sensitive for diagnosing effusion. Tamponade, although a clinical diagnosis, has characteristic TTE findings including chamber collapse and respiratory variation in mitral valve inflow velocity. ${ }^{6}$ Detecting malignant aetiology by TTE is limited by the ability to distinguish tumours from other pericardial echodensities. Effusions may result in cardiomegaly on CXR; mediastinal widening, hilar masses or pleural effusion may suggest a malignant cause. ${ }^{6}$ CT or MRI should be considered when TTE is inconclusive, or when loculation, haemorrhage or pericardial thickening are suspected. ${ }^{6}$ Pericardial masses or irregularity, associated lung or mediastinal changes or CT attenuation of effusion greater than that of water suggest malignancy. Most tumours have low signal intensity on T-1 and high signal intensity of T- 2 weighted MRI. ${ }^{8}$

$\mathrm{CP}$ is characterised by the encasement of the heart, with resultant diastolic dysfunction. Typical signs are those of congestive heart failure; elevated neck veins, oedema and hepatic congestion. More specific signs, Kussmaul's sign and pericardial knock are less frequent. ${ }^{9}$ CXR findings include pericardial calcification and pleural effusion. ${ }^{6}$ TTE may show suggestive findings including restrictive ventricular filling, ${ }^{6}{ }^{9}$ however diagnosis is usually not possible by TTE alone. Cardiac haemodynamics include increased atrial pressure with sharp $\mathrm{x}$ and $\mathrm{y}$ descents, end-diastolic pressure equalisation and a dip and plateau morphology of ventricular diastolic pressure ${ }^{69}$ which may be difficult to distinguish from restrictive cardiomyopathy. CT and MRI show characteristic morphological changes and pericardial thickening with greater sensitivity than echocardiography. CT is sensitive for pericardial calcification. MRI may depict anatomy, inflammation and functional changes ${ }^{8} 9$ and may be the best diagnostic test. 
Table 1 Frequency, clinical features, diagnosis, treatment and outcomes

\begin{tabular}{|c|c|c|}
\hline & Neoplastic pericardial effusion & Neoplastic CP \\
\hline Frequency & $\begin{array}{l}\text { Autopsy } \\
\text { } 0.2-6 \% \text {, death from all causes } \\
\text { Up to } 20 \% \text {, patients with malignancy } \\
\text { Patients undergoing pericardiocentesis } \\
\text { Neoplastic aetiology in } 9-39 \%{ }^{6} \\
\text { Presentation of unknown cancer in } 7.5 \%{ }^{4} \\
\text { Invasive procedure, known malignancy }{ }^{10} \\
\text { Tamponade in } 46 \%\end{array}$ & $\begin{array}{l}\text { Incidence } \\
2-5 \% \text { risk of CP following acute } \\
\text { neoplastic pericarditis }\end{array}$ \\
\hline Symptoms & $\begin{array}{l}\text { Autopsy proven pericardial malignancy } \\
\text { Asymptomatic in up to } 64 \% \\
\text { Small symptomatic pericardial effusion } \\
\text { Dyspnoea } 73-93 \% \\
\text { Chest pain } 61 \% \\
\text { Cough } 30 \% \\
\text { Invasive procedure, known malignancy } \\
\text { Dyspnoea } 81 \% \\
\text { Chest pain } 20 \%\end{array}$ & $\begin{array}{l}\text { Symptoms include (not malignancy specific) } \\
\text { Oedema } \\
\text { Abdominal swelling/discomfort } \\
\text { Dyspnoea } \\
\text { Cough }\end{array}$ \\
\hline Signs & $\begin{array}{l}\text { Invasive procedure, known malignancy } \\
\text { Pulsus paradoxus } 32 \% \\
\text { Peduced breath sounds } 26 \% \\
\text { - Tachycardia } 22 \% \\
\text { Peripheral oedema } 21 \% \\
\text { - Elevated JVP } 21 \% \\
\text { Hypotension } 21 \% \\
\text { - Pericardial rub } 15 \%\end{array}$ & $\begin{array}{l}\text { Signs include (not malignancy specific) } \\
\text { - Elevated JVP } 93 \% \\
\text { Peripheral oedema } 76 \% \\
\text { Hepatomegaly } 53 \% \\
\text { Pericardial knock/S3 } 47 \% \\
\text { Ascites } 37 \% \\
\text { Pleural effusion } 35 \% \\
\text { - } \text { Kussmaul's sign } 21 \% \\
\text { Pulsus paradoxus } 19 \%\end{array}$ \\
\hline Pathological diagnosis & $\begin{array}{l}\text { Cytology } \\
\text { Sensitivity: } 44-100 \%{ }^{4} 10-12 \\
\text { Specificity: } 93.3-100 \%{ }^{11} 12 \\
\text { Pericardial biopsy } \\
\text { Pericardiotomy has limited benefit over pericardiocentesis and extended drainage } \\
\text { Thoracotomy and open biopsy } \\
\text { Diagnosis in } 90 \% \text { with adequate sampling }\end{array}$ & \\
\hline Treatment and outcomes & $\begin{array}{l}\text { Pericardiocentesis for malignancy-related pericardial effusion, all cancers } \\
\text { Mean survival } 4 \text { months }{ }^{4} \\
\text { Poor prognostic factors }{ }^{10} \\
\text { Older } \\
\text { Tumour burden/advanced stage } \\
\text { Delayed diagnosis } \\
\text { Improved prognostic factors }{ }^{5} 10 \\
\text { Recurrent effusion } \\
\text { - Cheast, lymphoma } \\
\text { - Chensitive/radio-sensitive }\end{array}$ & $\begin{array}{l}\text { Pericardiectomy } \\
\text { Data confounded by concomitant radiation therapy } \\
\text { 10-year survival, neoplastic CP with } \\
\text { history of radiation }=30 \% \pm 13 \%^{15}\end{array}$ \\
\hline
\end{tabular}

Definitive diagnosis of malignancy requires cytology or histology. Pericardiocentesis should be performed when there is suspicion for neoplastic effusion. ${ }^{6} \mathrm{Up}$ to two-third of pericardial effusions in patients with malignancy are non-malignant..$^{5}$ Bloody pericardial effusion is suggestive. ${ }^{6}$ Sensitivity of cytology is between $44 \%$ and $100 \%,{ }^{4} 10-12$ due to variation in gold standard (biopsy, clinical follow-up or autopsy) and technical factors (fluid volume, number of pericardiocenteses and operator experience). ${ }^{4}$ Specificity of pericardial fluid cytology is between $93.3 \%$ and $100 \% .^{11}{ }^{12}$ Pericardial fluid tumour markers including CEA and CA 19-9 lack sufficient accuracy for diagnosis. ${ }^{6}$ With negative fluid analysis, pericardial biopsy may be considered; pericardioscopy may improve diagnostic yield. ${ }^{6}$ Surgical pericardiotomy may not improve diagnostic accuracy over pericardiocentesis with extended drainage. ${ }^{13}$ When minimally invasive techniques are non-diagnostic, thoracotomy and open biopsy may be necessary; histological diagnosis is possible in $90 \%$ with adequate tissue sampling. ${ }^{1}$ Diagnosis in our case was hampered by the frequency of non-malignant effusion and the broad range of sensitivities of pathological tests.
Tamponade requires emergent pericardiocentesis or surgical drainage. Treatment of large neoplastic pericardial effusions without tamponade should comprise when possible: systemic chemotherapy; pericardiocentesis to confirm aetiology and improve symptoms; prolonged pericardial drainage with tailored intrapericardial sclerosing or cytostatic agents to help prevent recurrence. ${ }^{6}$ Surgical pericardiotomy does not improve outcomes over pericardiocentesis with extended drainage and has more complications. ${ }^{13}$ Percutaneous balloon-pericardiotomy and pericardial window have a role in recurrent disease. ${ }^{13}$ Prognosis of malignancy-related pericardial effusion depends on age, disease burden, cancer type, chemo-sensitivity and radio-sensitivity. ${ }^{510}$ The mean survival in neoplastic pericarditis secondary to gastric carcinoma may be only 4.5 months. ${ }^{14}$

Definitive treatment of CP is pericardiectomy; however, palliative treatment of $\mathrm{CP}$ is often appropriate. ${ }^{6}$ Outcomes of pericardiectomy for neoplastic CP are confounded by grouping with postradiotherapy patients in clinical studies. ${ }^{15}$ Predictors of overall survival postpericardiectomy include age, left ventricle function, prior radiotherapy, pulmonary artery pressure, serum sodium and creatinine. $^{15}$ 
In summary, occult gastrointestinal malignancy may very rarely present as pericardial disease, its diagnosis may be challenging and outcomes are poor. One should maintain a high index of suspicion for pericardial malignancy when faced with a negative work-up. Frequencies, clinical features, diagnosis, treatment and outcomes are summarised in table 1.

\section{Learning points}

- Occult GI malignancy may rarely present as pericardial disease.

- Diagnosis of malignancy which initially presents as pericardial disease is challenging due to its rarity, obscuration by more common diagnoses and diagnostic accuracy of available investigations.

- Tumour markers may be considered to help distinguish benign from malignant pericardial effusions; however, they lack sufficient accuracy to reliably do so.

- Malignant pericardial disease is associated with a poor prognosis.

Contributors SPF and OA contributed equally to researching, writing and editing the manuscript. SF contributed the perioperative details. RBN wrote part of the discussion and edited the manuscript.

Competing interests None declared.

Patient consent Obtained.

Provenance and peer review Not commissioned; externally peer reviewed.

\section{REFERENCES}

1 Goldberg AD, Blankstein R, Padera RF. Tumors metastatic to the heart. Circulation 2013;128:1790-4.

2 Bussani R, De-Giorgio F, Abbate A, et al. Cardiac metastases. I Clin Pathol 2007;60:27-34.

3 Maisch B, Seferović PM, Ristic AD. Guidelines on the Diagnosis and Management of Pericardial diseases. Executive Summary; The Task force on the diagnosis and management of pericardial diseases of the European society of cardiology. Eur Heart J 2004;25:587-610.

4 Ben-Horin S, Bank I, Guetta V, et al. Large symptomatic pericardial effusion as the presentation of unrecognized cancer: a study in 173 consecutive patients undergoing pericardiocentesis. Medicine (Baltimore) 2006;85:49-53.

5 Retter AS. Pericardial disease in the oncology patient. Hear Dis 2002;4:387-91.

6 Adler Y, Charron P, Imazio M, et al. 2015 ESC Guidelines for the diagnosis and management of pericardial diseases: the Task Force for the Diagnosis and Management of Pericardial Diseases of the European Society of Cardiology (ESC)Endorsed by: the European Association for Cardio-Thoracic Surgery (EACTS). Eur Heart J 2015;36:2921-64.

7 Huang JY, Jiang HP, Chen D, et al. Primary gastric signet ring cell carcinoma presenting as cardiac tamponade. World I Gastrointest Oncol 2011;3:67-70.

8 Rienmüller R, Gröll R, Lipton MJ. CT and MR imaging of pericardial disease. Radiol Clin North Am 2004:42:587-601.

9 Syed FF, Schaff HV, Oh JK. Constrictive pericarditis-a curable diastolic heart failure. Nat Rev Cardiol 2014;11:530-44.

10 Wilkes JD, Fidias P, Vaickus L, et al. Malignancy-related pericardial effusion. 127 cases from the Roswell park cancer institute. Cancer 1995;76:1377-87.

11 Malamou-Mitsi VD, Zioga AP, Agnantis NJ. Diagnostic accuracy of pericardial fluid cytology: an analysis of 53 specimens from 44 consecutive patients. Diagn Cytopathol 1996;15:197-204.

12 Meyers DG, Meyers RE, Prendergast TW. The usefulness of diagnostic tests on pericardial fluid. Chest 1997;111:1213-21.

13 Patel N, Rafique AM, Eshaghian S, et al. Retrospective comparison of outcomes, diagnostic value, and complications of percutaneous prolonged drainage versus surgical pericardiotomy of pericardial effusion associated with malignancy. Am J Cardiol 2013;112:1235-9.

14 Kobayashi M, Okabayashi T, Okamoto K, et al. Clinicopathological study of cardiac tamponade due to pericardial metastasis originating from gastric cancer. World J Gastroenterol 2005;11:6899.

15 Bertog SC, Thambidorai SK, Parakh K, et al. Constrictive pericarditis: etiology and cause-specific survival after pericardiectomy. J Am Coll Cardiol 2004;43:1445-52.

Copyright 2017 BMJ Publishing Group. All rights reserved. For permission to reuse any of this content visit

http://group.bmj.com/group/rights-licensing/permissions.

BMJ Case Report Fellows may re-use this article for personal use and teaching without any further permission.

Become a Fellow of BMJ Case Reports today and you can:

- Submit as many cases as you like

- Enjoy fast sympathetic peer review and rapid publication of accepted articles

- Access all the published articles

- Re-use any of the published material for personal use and teaching without further permission

For information on Institutional Fellowships contact consortiasales@bmjgroup.com

Visit casereports.bmj.com for more articles like this and to become a Fellow 